\title{
Use of Liquid-Based Cytology (LBC) and Cell Blocks from Cell Remnants for Cytologic, Immunohistochemical, and Immunocytochemical Diagnosis of Malignancy ${ }^{*}$
}

\author{
Hirofumi Sakamoto, Makiyo Takenaka, Kazuki Ushimaru, Takuji Tanaka \\ Department of Cytology, The Tohkai Cytopathology Institute, Cancer Research and Prevention (TCI-CaRP), Gifu City, Japan. \\ Email: takutt@toukaisaibou.co.jp
}

Received April 10"th 2012; revised May 10 ${ }^{\text {th }}$, 2012; accepted May 20 ${ }^{\text {th }}, 2012$

\begin{abstract}
Great advances in screening have lowered the death rate from cervical cancer in the advanced countries. The major advances in cervical cancer screening include the Papanicolaou (Pap) test and liquid-based cytology (LBC). In this study, we aimed to use cell remnants from LBC specimens from uterine cervix and endometrium, aspirates from breast and thyroid tumors, and liquid samples (ascites, pleural effusion, and urine). Cell blocks made from cell remnants of LBC specimens were immunohistochemically or immunocytochemically stained for several biomarkers including certain tumor markers such together with hematoxylin and eosin staining for accurate diagnosis of malignancies in different samples. The findings from the cell blocks stained with these biomarkers combined with those from Pap stain led to easily diagnosis of the presence or absence of malignancies. Our findings suggest the utility of LBC and cell blocks from cell remnants in cytologic diagnosis in certain specimens.
\end{abstract}

Keywords: LBC; Cell Remnants; Cell Block; Immunohistohemistry; Immunocytochemistry; Biomarkers; Cancer; Accurate Diagnosis

\section{Introduction}

A technique, liquid-based cytology (LBC), enables cells to be suspended in a monolayer. LBC makes better cytological assessment possible with improved sensitivity and specificity, since fixation is better and nuclear details are well preserved in the technique. Preneoplastic and neoplastic cells are not obscured by other cells, such as normal epithelial and inflammatory cells [1-5]. This method involves collection of specimens directly into a liquid fixative, but in the case cervical specimens, a brushlike device, Cervex-brush (Rovers medical devices) is utilized. The brush is used to scrape the cervix. The brush head is then detached and immediately put into a vial containing a special commercial fixative solution, such as SurePath preservative fluid [1-5]. Smears are made from the sediment, stained and cytologically diagnosed. At present, two techniques, Thin Prep (Cytyc Corp.) and SurePap (Tripath imaging, Inc.), have been more widely used for screening and diagnosing for cervical lesions [1-5]. Using LBC, the rate of colposcopic examinations for repeated unsatisfactory conventional Papanicolaou (Pap) smears has fallen from almost 25\% to $0.5 \%$ and the percentage of unsatisfactory PAP smears

\footnotetext{
*Conflict of interest: None declared.
}

has fallen from $13.6 \%$ to $1.9 \%$ [6]. Thus, LBC has improved unsatisfactory conventional Pap smear rates and give significant benefits to colposcopic examinations. Moreover, LBC technique shortens laboratory turnaround times. The superiority of the quality of LBC in comparison with those of conventional Pap smears has been described $[2,7,8]$. The sensitivities of the conventional Pap smear and LBC tests are estimated to be $70 \%$ $80 \%$ and $85 \%$ - 95\%, respectively [9]. LBC is currently recommended for cervical cancer screening [10] with a major advantage of allowing ancillary techniques such as those used in immunocytochemistry and molecular biology [11-17]. Cell blocks made from cell or tissue remnants of LBC can also be used for immunocytochemistry or immunohistochemistry of specific biomarkers to accurate diagnosis of malignancy [16-19]. In addition, LBC has currently been used for non-gynecologic cytology [15,17,19-22].

The aim of the present study was to determine whether immunocytochemistry and immunohistochemistry of nongynecologic and gynecologic LBC specimens and cellblockes made from the remnant of cells in a brush-like device, which are meant to be discarded after LBC cytology, possesses diagnostic value for malignancies. Eva- 
luation was performed on the LBC specimens of urine, breast fine needle aspiration, body fluid (pleural effusions and ascites), cervix, and endometrium.

\section{Materials and Methods}

\subsection{Sample Collection and Preparation}

A total of 58 LBC samples that were suspected for proliferative lesions or malignancy were collected for this study. They included 24 gynecological samples (14 cervix and 10 endometrium) and non-gynecological specimens (4 fresh voided urines, 7 breast and 7 thyroid tumors aspirates, 8 ascites and 8 pleural fluid). These were from 58 patients with known or unknown carcinoma, which were obtained from 5 different municipal hospitals and 10 clinics in Gifu City, Japan. All the patients provided informed consent. These SurePath samples were processed using the BD PrepStain ${ }^{\mathrm{TM}}$ Slide Processor, BD SurePath ${ }^{\mathrm{TM}}$ Cell Enrichment, and BD CytoRich ${ }^{\mathrm{TM}}$ System (BD Japan, Co., Ltd., Tokyo, Japan) according to the manufacturer's instructions, and then cytological diagnosis was made on each case.

\subsection{Preparation of Cell Blocks}

Residual specimens collected in PreservCyt solution from gynecological samples used for thrombin cell block preparation. Cell blocks were prepared primarily according to the method described by Keyhani-Rofagha and Vesey-Shecket [23] and Yang et al., [24]. In brief, the residual SurePath sample was placed in a $50 \mathrm{~mL}$ Falcon tube and spun in Beckman Coulter Allegra 6 Centrifuge (Beckman Coulter, Fullerton, Calif) for 10 minutes at $2000 \mathrm{rpm}$. The supernatant was poured off, which left the small pellet/button in the bottom of the tube. Approximately 5 drops of plasma were added to the cell button to resuspend it. Then approximately 5 drops of bovine thrombin (Fisher Scientific Item \# 23-306291; Thermo Fisher Scientific, Waltham, Mass) were added, and the mixture was allowed to stand for 10 minutes. The cell pellet was fixed in $10 \%$ formalin for 10 minutes. The cell block materials were transferred to biopsy bags by pouring the contents of the Falcon tube into a biopsy bag over a funnel and beaker. The cell block materials in the biopsy bags were placed into a histology cassettes. The cassettes were processed as routine surgical specimens.

Fresh effusions, including voided urines, ascites, and pleural fluids, were centrifuged and sediments were used to make cell blocks by plasma-thrombin method. Briefly, after decanting supernatant, several drops of plasma and thrombin were added to the sediments to mix by gentle vortex and the mixture was then allowed to clot, followed by fixation with $10 \%$ buffered formalin solution for at least 1 hour before being processed for embedding in paraffin blocks.

\subsection{Immunohistochemical and Immunocytochemical Stainings}

Slides made from cell blocks and LBC specimens were treated in the BenchMark XT Automated Slide Preparation System (Roche Diagnostics Japan, K.K., Tokyo) using a 3,3'-diaminobenzidine kit, and were slightly counterstained with Harris haematoxylin, according to the manufacturer's instructions. Negative controls were prepared by use of CONFIRM Negative Control Mouse Ig (MOPC-21, Ventana Japan, Co., Ltd., Yokohama City, Japan) and CONFIRM Negative Control Rabbit Ig (Polyclonal, Ventana Japan, Co., Ltd.) exclusion of the primary antibody. Known positive controls were also included. Antibodies for immunocytochemistry and immunohistochemistry used in this study included p16, p53, p63, CK20, Ki-67, CD10, CD45, CD56, estrogen recaptor (ER), thyroid transcription factor 1 (TTF-1), carcinoembryonic antigen (CEA), $\beta$-catenin, carbohydrate antigen 19-9 (CA19-9), calretinin, and human epidermal growth factor receptor 2 (Her2). Their sources are listed in Table 1.

\section{Results}

Uterine cervix LBC samples were cytoplogically diagnosed as 2 ASC-H, 2 HSIL (severe dysplasia), 3 carcinoma in situ (CIS), 5 squamous cell carcinomas (SCCs) or 2 adenocarcinomas. The remnants were obtained from

Table 1. The antibodies used in this study, their suppliers, dilutions, and positive controls.

\begin{tabular}{cccc}
\hline Antibodies & Suppliers & Dilutions & Positive controls \\
\hline P16 & BD & $1: 10$ & Breast cancer \\
P53 & Ventana/Roche & $*$ & Colon cancer \\
P63 & Ventana/Roche & $*$ & Prostate \\
CK20 & Ventana/Roche & $*$ & Colon cancer \\
Ki-67 & Ventana/Roche & $*$ & Tonsil \\
CD10 & Ventana/Roche & $*$ & Tonsil \\
CD45R & Ventana/Roche & $*$ & Tonsil \\
CD56 & Ventana/Roche & $*$ & Small intestine \\
ER & Ventana/Roche & $*$ & Breast \\
TTF-1 & Ventana/Roche & $*$ & Lung cancer \\
CEA & DAKO & $1: 50$ & Colon cancer \\
$\beta$-catenin & Ventana/Roche & $*$ & Breast cancer \\
CA19-9 & Ventana/Roche & $*$ & Colon cancer \\
Calretinin & Ventana/Roche & $*$ & Brain \\
Her2 & Ventana/Roche & $*$ & Breast cancer \\
\hline
\end{tabular}

*Diluted by the supplier. 
the samples suspected of CIS, SCC, and adenocarcinoma. We confirmed their diagnoses on the histologic slides stained with hematoxylin and eosin (H \& E) from cell blocks. Endometrial LBC samples were diagnosed atypical 2 endometrial hyperplasias and 8 endometrioid adenocarcinomas. They also were confirmed on their $\mathrm{H} \&$ E-stained histologic slides from cell blocks. Seven breast tumor aspirates and 7 thyroid tumor aspirates were cytologically diagnosed as breast cancers (6 papillotubular carcinoma and 1 intracystic papillary carcinoma) and papillary carcinomas, respectively on their LBC slides, and the diagnoses were confirmed by histological examination using the respective blocks. All of 4 voided urine LBC samples were cytologically urothelial carcinomas and this diagnosis was confirmed histologically on $\mathrm{H} \&$ E-stained sections made from the respective blocks. Cytological diagnoses of eight ascites were all adenocarcinoma from malignancies of digestive tissues (5 of colorectal and 3 of stomach cancers). These diagnoses were histopathologically confirmed on $\mathrm{H}$ \& E-stained histologic sections made from the respective blocks. Eight pleural fluids LBC specimens were cytologically diagnosed as 7 adenocarcinomas from lung cancers and one malignant mesothelioma. The diagnosis of these cases was confirmed by histological investigation on $\mathrm{H}$ \& E-stained histologic sections made from the respective blocks.

Cytological, histological, immunocytochemical, im- munohistolochemical findings on some of these cases are shown in Figures 1-6. A case of cervical LBC sample that was not clinically suspected of malignancy showed HSIL, possible CIS (Figure 1(a)). Histopathological examination in the cell block specimen suggested CIS (Figure 1(b)). Cancer cells were immunohistochemically positive for Ki-67 (Figure 1(c)) in their nuclei, $\beta$-catenin (Figure 1(d)) in their cell membrane and cytoplasm, and p16 (Figure 1(d)) in their nuclei as well as cytoplasm. An endometrial LBC sample showing atypical endometrial hyperplasia (Figure 2(a)) was finally diagnosed as moderately-differentiated adenocarcinoma (Figure 2(b)) with positive reactivity for ER antibody (Figure 2(c)) in the cell block specimen. An aspirate from the thyroid tumor was cytologically suspected follicular tumor (Figure 3(a)) and subsequent histological examination in the cell block specimen revealed papillary carcinoma (Figure 3(b)) that was positive for TTF-1 (Figure 3(c)). A breast tumor aspirate was cytologically suspicious of papillotubular carcinoma (Figure 4(a)) and this was confirmed by histological examination (Figure 4(b)) and Her2 immunohistochemistry (Figure 4(c)) in the cell block specimen. A LBC specimen from a patient with ascites showed a cluster of atypical glandular cells containing signet-ring cells (Figure 5(a)). In the cell block specimen from this LBC specimen, there were numerous adenocarcinoma cells containing signet-ring cells (Figure 5(b)) with positive reaction for Ki-67 antibody
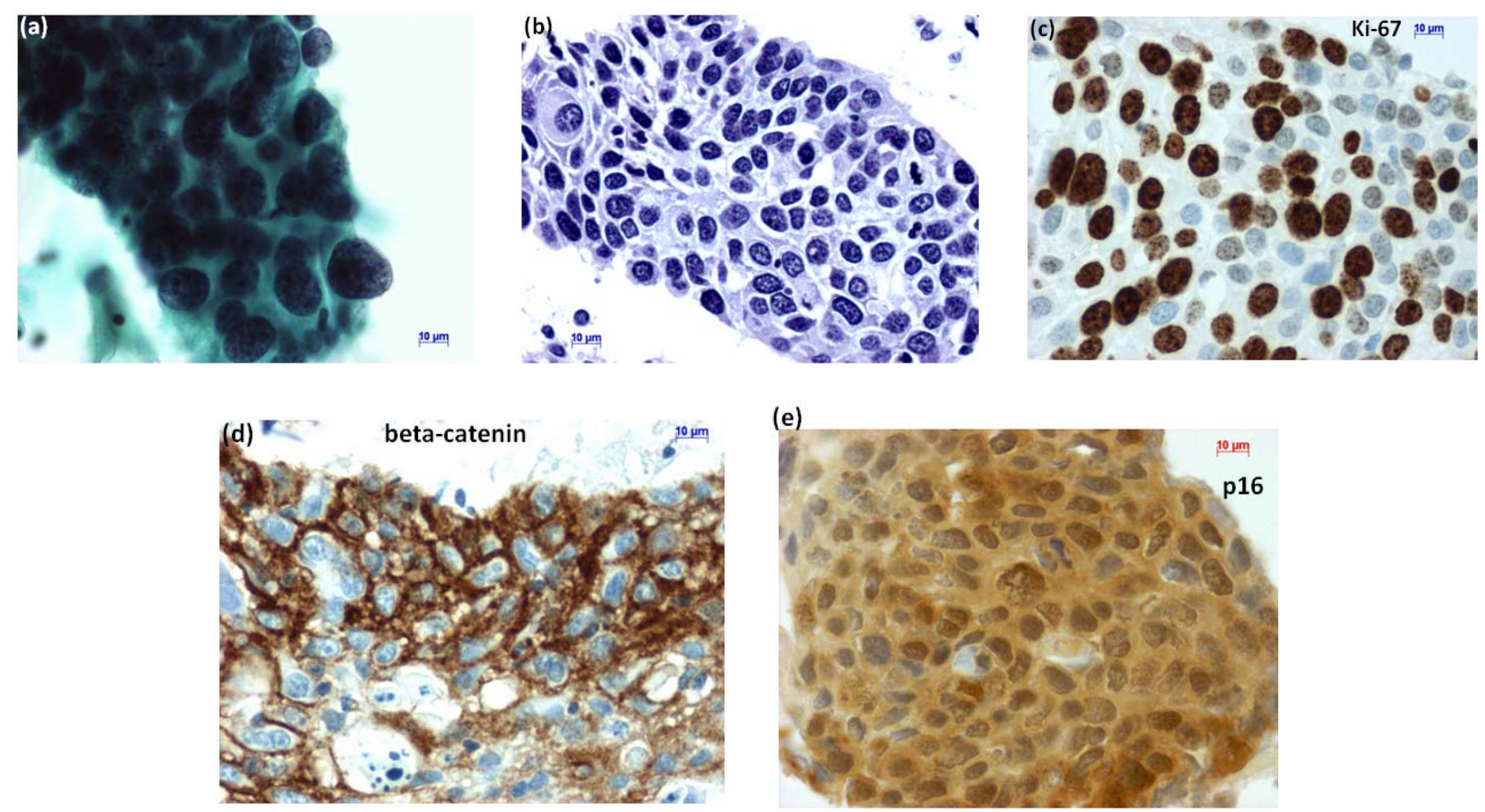

Figure 1. (a) LBC showed a cluster of atypical squamous cells, suggesting CIS (Pap stain); (b) Histopathology of the cell block tissue from remnant of LBC indicated CIS (H \& E stain); Immunohistochemistry of (c) Ki-67; (d) $\beta$-catenin; and (e) p16 showed positive reaction for these antibodies. Bars are $10 \mu \mathrm{m}$. 

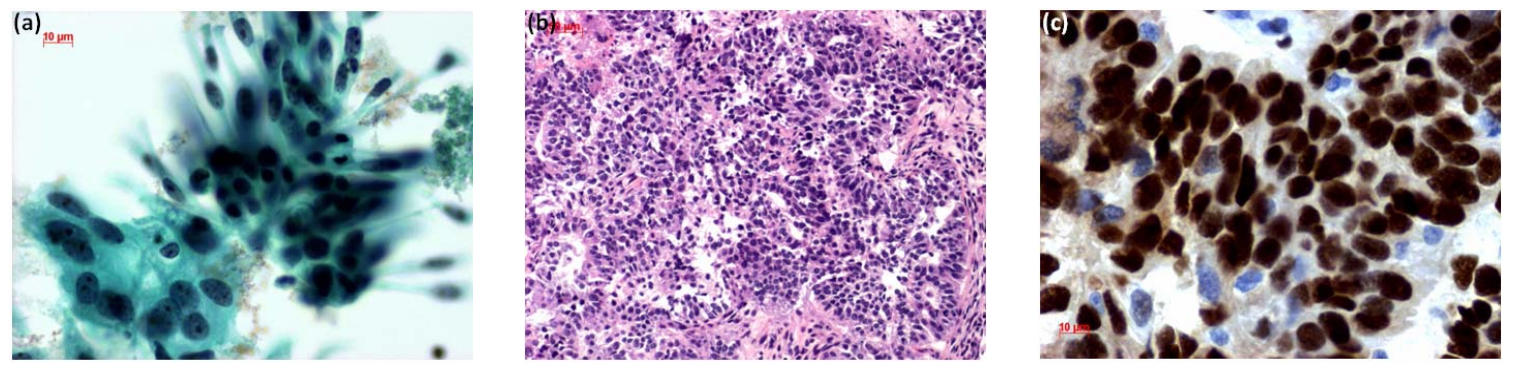

Figure 2. (a) Endometrial LBC showed a papillary cluster containing a tubular pattern (arrow), suggesting atypical endometrial hyperplasia (Pap stain, bar $=10 \mu \mathrm{m}$ ); (b) Histopathology of the cell block section from LBC sample indicated moderately-differentiated adenocarcinoma (H \& E stain, bar = $50 \mu \mathrm{m}$ ); (c) Endometrial cancer cells on a cell block section were immunohistochemically positive for ER antibody (ER immunohistochemistry, bar $=10 \mu \mathrm{m}$ ).
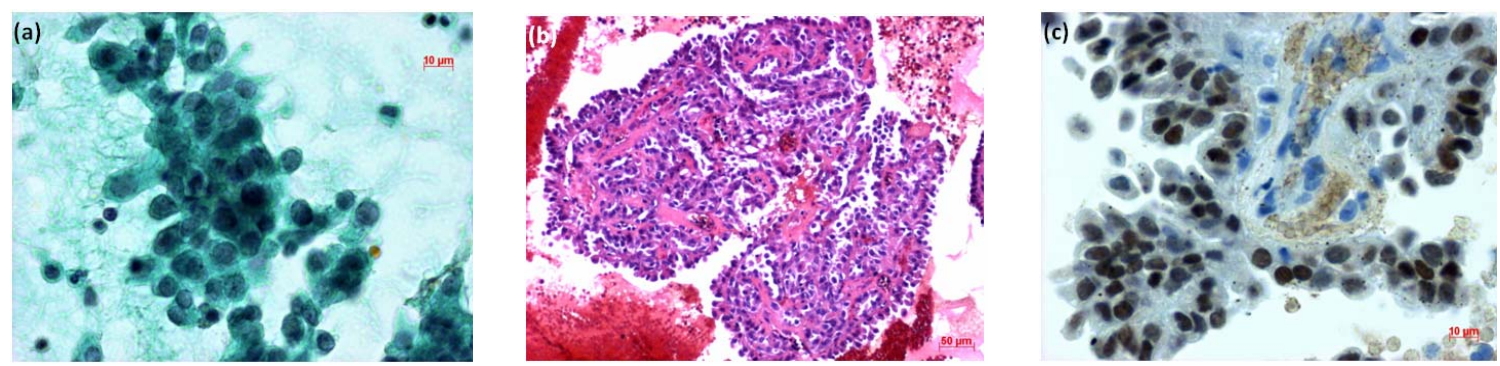

Figure 3. (a) LBC of thyroid tumor aspirates showed a cluster containing atypical follicular cells, suggesting follicular tumor (Pap stain, bar = $10 \mu \mathrm{m}$ ); (b) Histopathology of the cell block section from the aspirate indicated papillary carcinoma (H \& $\mathrm{E}$ stain, bar = $50 \mu \mathrm{m}$ ); (c) Thyroid cancer cells on a cell block section were immunohistochemically positive for TTF-1 antibody (TTF-1 immunohistochemistry, bar $=10 \mu \mathrm{m})$.
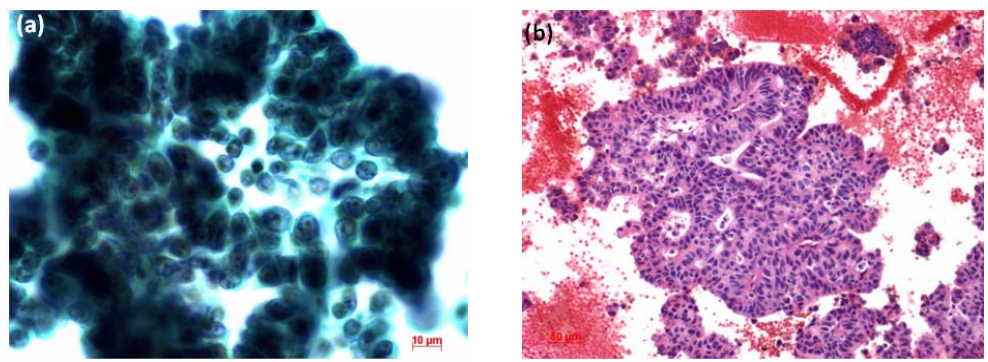

(c)

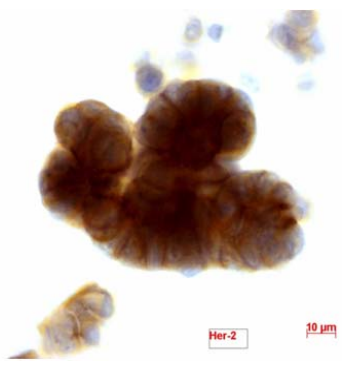

Figure 4. (a) LBC of breast tumor aspirates showed a papillary cluster containing atypical ductal cells, suggesting papillotubular carcinoma (Pap stain, bar $=10 \mu \mathrm{m}$ ); (b) Histopathology of the cell block section from the aspirate confirmed the cytological diagnosis (H \& E stain, bar = $50 \mu \mathrm{m}$ ); (c) Breast cancer cells on a cell block section were immunohistochemically positive for Her2 antibody (Her2 immunohistochemistry, bar $=10 \mu \mathrm{m}$ ).
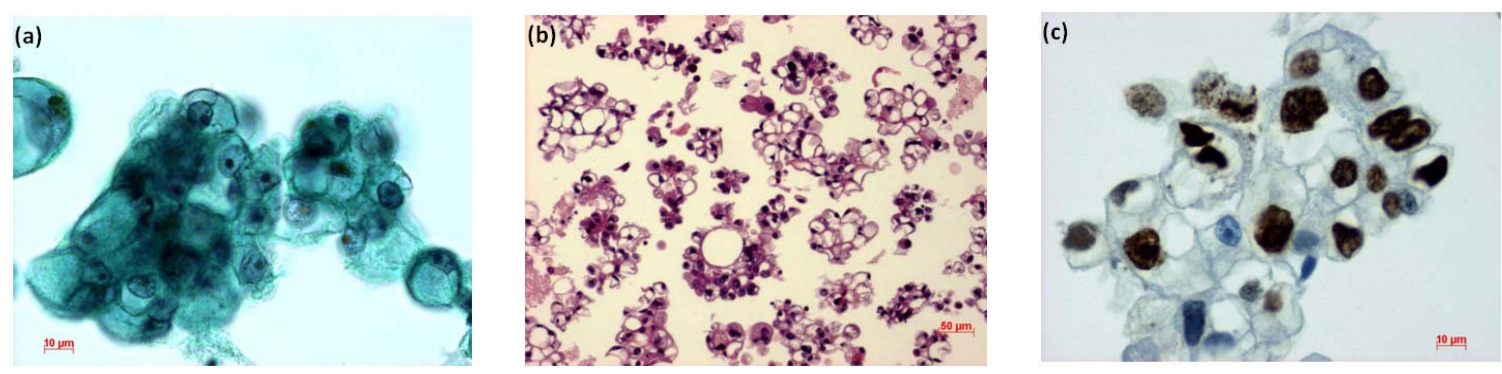

Figure 5. LBC of ascites showed presence of adenocarcinoma with signet-ring cells in the fluids (Pap stain, bar = $10 \mu \mathrm{m})$; $(\mathrm{b})$ Histopathology of the cell block section from the LBC sample indicated signet-ring cell carcinoma (H \& E stain, bar = $50 \mu \mathrm{m})$; (c) Cancer cells on a cell block section were immunohistochemically positive for Ki-67 antibody (Ki-67 immunohistochemistry, bar $=10 \mu \mathrm{m})$. 

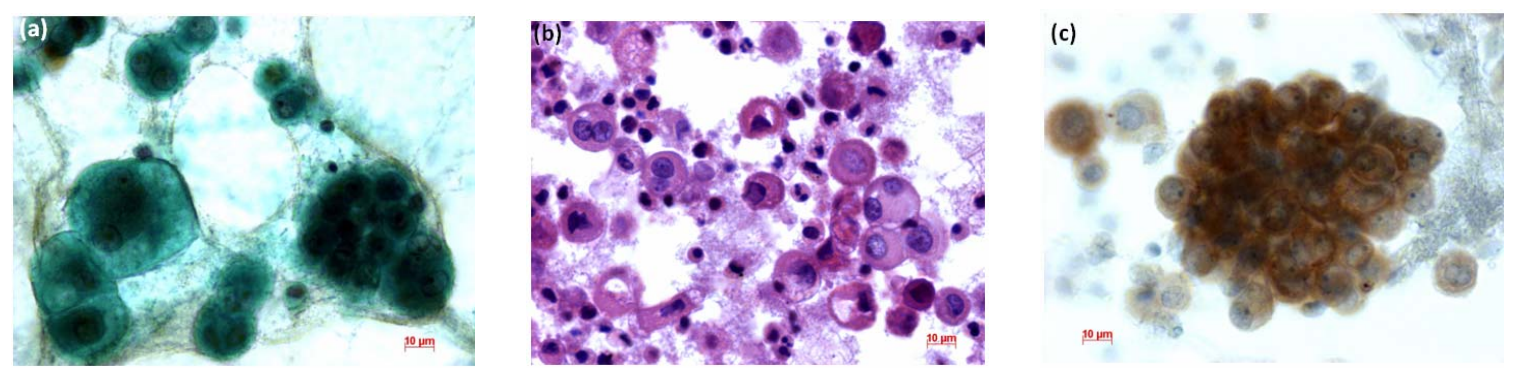

Figure 6. (a) LBC of pleural fluid showed atypical mesothelial cells, suggesting malignant mesothelioma (Pap stain); (b) Histopathology of the cell block tissue from the LBC smaple indicated malignant mesothelioma (H \& E stain); (c) Immunohistochemistry of calretinin showed positive reaction. Bars are $10 \mu \mathrm{m}$.

(Figure 5(c)), and finally diagnosed peritonitis carcinomatosa of gastric signet-ring cell carcinoma. In the LBC sample from a patient with pleural effusion, atypical mesothelial cells (Figure 6(a)). We suspected malignant mesothelioma from the cytological findings and this was confirmed by histopathological findings from the cell block specimen (Figure 6(b)) of this LBC specimen. The mesothelioma cells in the LBC specimen were immunocytochemically positive for calretinin antibody (Figure 6(c)).

\section{Discussion}

In this study, we showed utility of the LBC method in both gynecological and non-gynecological samples. Moreover, cell block made from the LBC samples and their remnants were useful for accurate diagnosis. Immunocytochemical and immunohistochemical techniques that were applied in the LBC and cell block specimens were further helpful for the diagnosis.

The LBC method is currently used for uterine cervical cancer screening $[2,3,25,26]$ with immunocytochemical detection of human papilloma virus (HPV) and positivity of $\mathrm{p} 16^{\mathrm{INK} 4 \mathrm{a}}$ [13,27]. We [19] and other researchers $[18,28,29]$ have reported that cell block sections from residual SurePath or ThinPrep samples and other LBC samples including aspirates and body fluids are helpful with certain problematic cases, such as metastatic tumor of unknown origin and lesions need to be differential diagnosis. In this study, we could immunohistochemically detect positivity of p16 $6^{\text {INK4a }}$ in CIS of the cell block specimens. Moreover, Ki-67 positivity and $\beta$-catenin stainability were also found in the CIS lesion.

LBC techniques are currently applied to cytological samples from several tissues or fluids other than uterine cervix. They include endometrium [30-33], aspirates from breast [34,35] and thyroid tumors [36,37], ascites and pleural effusion [38], and urine [39-46]. Moreover, LBC technology is suggested as an appropriate diagnostic method for metastatic tumors in cerebrospinal fluid [47] and other samples [48].
In conclusion, LBC with immunocytochemistry and cell block sections with immunohistochemistry result in enhanced specimen quality, and accurate diagnosis, and diminished false negative cases. LBC has potential as a screening tool for cancer and precancerous lesions in several tissues other than gynecologic organs. Cell block tissues made from remnants and residual LBC samples, aspirates, and fluid samples may also have applications for practice in the field of cytopathology.

\section{Acknowledgements}

This work was partly supported by a Grant-in-Aid for the $2^{\text {nd }}$ and $3^{\text {rd }}$ Terms Comprehensive 10-year Strategy for Cancer Control, Cancer Prevention, from the Ministry of Health and Welfare of Japan, a Grant-in-Aid for Cancer Research from the Ministry of Health and Welfare of Japan, and a Grant-in-Aid (no. 13671986 and no. 23501324) from the Ministry of Education, Science, Sports and Culture of Japan.

\section{REFERENCES}

[1] A. N. Kavatkar, C. A. Nagwanshi and S. M. Dabak, "Study of a Manual Method of Liquid-Based Cervical Cytology," Indian Journal of Pathology and Microbiology, Vol. 51, No. 2, 2008, pp. 190-194. doi:10.4103/0377-4929.41678

[2] R. K. Gibb and M. G. Martens, "The Impact of Liquid-Based Cytology in Decreasing the Incidence of Cervical Cancer," Reviews in Obstetrics and Gynecology, Vol. 4, Suppl. 1, 2011, pp. S2-S11.

[3] C. Hamashima, D. Aoki, E. Miyagi, E. Saito, T. Nakayama, M. Sagawa, H. Saito and T. Sobue, "The Japanese Guideline for Cervical Cancer Screening,” Japanese Journal of Clinical Oncology, Vol. 40, No. 6, 2010, pp. 485-502. doi:10.1093/jico/hyq036

[4] D. Saslow, C. D. Runowicz, D. Solomon, A. B. Moscicki, R. A. Smith, H. J. Eyre and C. Cohen, "American Cancer Society Guideline for the Early Detection of Cervical Neoplasia and Cancer,” Journal of Lower Genital Tract Disease, Vol. 7, No. 2, 2003, pp. 67-86.

doi:10.1097/00128360-200304000-00001 
[5] A. G. Siebers, P. J. Klinkhamer, J. M. Grefte, L. F. Massuger, J. E. Vedder, A. Beijers-Broos, J. Bulten and M. Arbyn, "Comparison of Liquid-Based Cytology with Conventional Cytology for Detection of Cervical Cancer Precursors: A Randomized Controlled Trial,” JAMA, Vol. 302, No. 16, 2009, pp. 1757-1764. doi:10.1001/jama.2009.1569

[6] A. R. Williams, "Liquid-Based Cytology and Conventional Smears Compared over Two 12-Month Periods," Cytopathology, Vol. 17, No. 2, 2006, pp. 82-85. doi:10.1111/j.1365-2303.2006.00339.x

[7] C. Bergeron and F. Fagnani, "Performance of a New, Liquid-Based Cervical Screening Technique in the Clinical Setting of a Large French Laboratory," Acta Cytologica, Vol. 47, No. 5, 2003, pp. 753-761. doi:10.1159/000326601

[8] B. Weynand, M. Berliere, E. Haumont, F. Massart, A. Pourvoyeur, P. Bernard, J. Donnez and C. Galant, "A New, Liquid-Based Cytology Technique,” Acta Cytologica, Vol. 47, No. 2, 2003, pp. 149-153. doi:10.1159/000326495

[9] D. D. Davey and R. J. Zarbo, "Human Papillomavirus Testing-Are You Ready for a New Era in Cervical Cancer Screening?" Archives of Pathology \& Laboratory Medicine, Vol. 127, No. 8, 2003, pp. 927-929.

[10] C. Garbar, C. Mascaux and V. Fontaine, "Efficiency of an Inexpensive Liquid-Based Cytology Performed by Cytocentrifugations: A Comparative Study Using the Histology as Reference Standard,” Cytojournal, Vol. 2, 2005, p. 15.

[11] M. Bibbo, W. J. Klump, J. DeCecco and A. J. Kovatich, "Procedure for Immunocytochemical Detection of P16INK4A Antigen in Thin-Layer, Liquid-Based Specimens," Acta Cytologica, Vol. 46, No. 1, 2002, pp. 25-29. doi:10.1159/000326711

[12] L. Luzzatto, C. van Haaften and M. E. Boon, "Proliferation Patterns of Cervical Cells as Visualized in Leiden Liquid Cytology Slides," Diagnostic Cytopathology, Vol. 31, No. 1, 2004, pp. 5-9. doi:10.1002/dc.20011

[13] V. B. Carydis, T. Walker, A. Wing and T. J. Colgan, "Utility of p16(ink4a) Immunocytochemistry in Liquid-Based Cytology Specimens from Women Treated for High-Grade Squamous Intraepithelial Lesions," Acta Cytologica, Vol. 51, No. 4, 2007, pp. 517-522. doi: $10.1159 / 000325787$

[14] I. S. Kirbis, P. Maxwell, M. S. Flezar, K. Miller and M. Ibrahim, "External Quality Control for Immunocytochemistry on Cytology Samples: A Review of UK NEQAS ICC (Cytology Module) Results," Cytopathology, Vol. 22, No. 4, 2011, pp. 230-237. doi:10.1111/j.1365-2303.2011.00867.x

[15] R. Navone, M. Pentenero and S. Gandolfo, "LiquidBased Cytology in Oral Cavity Squamous Cell Cancer," Current Opinion in Otolaryngology \& Head and Neck Surgery, Vol. 19, No. 2, 2011, pp. 77-81. doi:10.1097/MOO.0b013e328343af10

[16] V. B. Shidham, R. Mehrotra, G. Varsegi, K. L. D’Amore, B. Hunt and R. Narayan, "p16 Immunocytochemistry on
Cell Blocks as an Adjunct to Cervical Cytology: Potential Reflex Testing on Specially Prepared Cell Blocks from Residual Liquid-Based Cytology Specimens," Cytojournal, Vol. 8, 2011, p. 1. doi:10.4103/1742-6413.76379

[17] G. M. Varsegi and V. Shidham, "Cell Block Preparation from Cytology Specimen with Predominance of Individually Scattered Cells,” Journal of Visualized Experiments, Vol. 29, 2009, Article ID: e1316.

[18] H. Liu, J. Shi, M. Wilkerson, Y. Huang, S. Meschter, W. Dupree and F. Lin, "Immunohistochemical Detection of p16INK4a in Liquid-Based Cytology Specimens on Cell Block Sections,” Cancer, Vol. 111, No. 2, 2007, pp. 7482. doi:10.1002/cncr.22577

[19] H. Sakamoto, K. Ushimaru, N. Miwa and T. Tanaka, "Application of Liquid-Based Cytology Cervical Cytologic Specimens to Cell Block for Histologic Observation (in Japanese)," Journal of the Japanese Society of Clinical Cytology, Vol. 49, No. 6, 2010, pp. 449-450. doi:10.5795/jiscc.49.449

[20] R. S. Hoda, "Non-Gynecologic Cytology on LiquidBased Preparations: A Morphologic Review of Facts and Artifacts,” Diagnostic Cytopathology, Vol. 35, No. 10, 2007, pp. 621-634. doi:10.1002/dc.20698

[21] J. Linder, "Recent Advances in Thin-Layer Cytology," Diagnostic Cytopathology, Vol. 18, No. 1, 1998, pp. 2432. doi:10.1002/(SICI)1097-0339(199801)18:1<24::AID-DC 5>3.0.CO;2-U

[22] N. A. Young, A. T. Moriarty, J. C. Haja and D. C. Wilbur, "Fine-Needle Aspiration Biopsy of Lymphoproliferative Disorders-Interpretations Based on Morphologic Criteria Alone: Results from the College of American Pathologists Interlaboratory Comparison Program in Nongynecologic Cytopathology," Archives of Pathology \& Laboratory Medicine, Vol. 130, No. 12, 2006, pp. 17661771.

[23] S. Keyhani-Rofagha and M. Vesey-Shecket, "Diagnostic Value, Feasibility, and Validity of Preparing Cell Blocks from Fluid-Based Gynecologic Cytology Specimens," Cancer, Vol. 96, No. 4, 2002, pp. 204-209. doi:10.1002/cncr.10716

[24] G. C. Yang, L. S. Wan, J. Papellas and J. Waisman, "Compact Cell Blocks. Use for Body Fluids, Fine Needle Aspirations and Endometrial Brush Biopsies,” Acta Cytologica, Vol. 42, No. 3, 1998, pp. 703-706. doi:10.1159/000331830

[25] D. Saslow, D. Solomon, H. W. Lawson, M. Killackey, S. L. Kulasingam, J. Cain, F. A. Garcia, A. T. Moriarty, A. G. Waxman, D. C. Wilbur, N. Wentzensen, L. S. Downs, Jr., M. Spitzer, A. B. Moscicki, E. L. Franco, M. H. Stoler, M. Schiffman, P. E. Castle and E. R. Myers, “American Cancer Society, American Society for Colposcopy and Cervical Pathology, and American Society for Clinical Pathology Screening Guidelines for the Prevention and Early Detection of Cervical Cancer," American Journal of Clinical Pathology, Vol. 137, No. 4, 2012, pp. 516-542. doi:10.1309/AJCPTGD94EVRSJCG

[26] D. Saslow, D. Solomon, H. W. Lawson, M. Killackey, S. 
L. Kulasingam, J. Cain, F. A. Garcia, A. T. Moriarty, A. G. Waxman, D. C. Wilbur, N. Wentzensen, L. S. Downs, Jr., M. Spitzer, A. B. Moscicki, E. L. Franco, M. H. Stoler, M. Schiffman, P. E. Castle and E. R. Myers, “American Cancer Society, American Society for Colposcopy and Cervical Pathology, and American Society for Clinical Pathology Screening Guidelines for the Prevention and Early Detection of Cervical Cancer," CA: A Cancer Journal for Clinicians, 2012, in Press. doi:10.3322/caac.21139

[27] J. Monsonego, G. Pollini, M. J. Evrard, P. Sednaoui, L. Monfort, D. Quinzat, R. Dachez and K. Syrjanen, "P16 (INK4a) Immunocytochemistry in Liquid-Based Cytology Samples in Equivocal Pap Smears: Added Value in Management of Women with Equivocal Pap Smear," Acta Cytologica, Vol. 51, No. 5, 2007, pp. 755-766. doi:10.1159/000325839

[28] G. P. Yeoh and K. W. Chan, "Cell Block Preparation on Residual ThinPrep Sample,” Diagnostic Cytopathology, Vol. 21, No. 6, 1999, pp. 427-431. doi:10.1002/(SICI)1097-0339(199912)21:6<427::AID-D C12>3.0.CO;2-4

[29] L. Yu, L. Wang, J. Zhong and S. Chen, "Diagnostic Value of p16INK4A, Ki-67, and Human Papillomavirus L1 Capsid Protein Immunochemical Staining on Cell Blocks from Residual Liquid-Based Gynecologic Cytology Specimens,” Cancer Cytopathology, Vol. 118, No. 1, 2010, pp. 47-55. doi:10.1002/cncy.20061

[30] B. R. Kipp, F. Medeiros, M. B. Campion, T. J. Distad, L. M. Peterson, G. L. Keeney, K. C. Halling and A. C. Clayton, "Direct Uterine Sampling with the Tao Brush Sampler Using a Liquid-Based Preparation Method for the Detection of Endometrial Cancer and Atypical Hyperplasia: A Feasibility Study,” Cancer, Vol. 114, No. 4, 2008, pp. 228-235. doi:10.1002/cncr.23636

[31] M. Papaefthimiou, H. Symiakaki, P. Mentzelopoulou, A. Tsiveleka, A. Kyroudes, Z. Voulgaris, A. Tzonou and P. Karakitsos, "Study on the Morphology and Reproducibility of the Diagnosis of Endometrial Lesions Utilizing Liquid-Based Cytology," Cancer, Vol. 105, No. 2, 2005, pp. 56-64. doi:10.1002/cncr.21025

[32] M. Thrall, K. Kjeldahl, H. E. Gulbahce and S. E. Pambuccian, "Liquid-Based Papanicolaou Test (SurePath) Interpretations before Histologic Diagnosis of Endometrial Hyperplasias and Carcinomas: Study of 272 Cases Classified by the 2001 Bethesda System,” Cancer, Vol. 111, No. 4, 2007, pp. 217-223. doi:10.1002/cncr.22770

[33] J. Watanabe, Y. Nishimura, S. Tsunoda, M. Kawaguchi, I. Okayasu and H. Kuramoto, "Liquid-Based Preparation for Endometrial Cytology-Usefulness for Predicting the Prognosis of Endometrial Carcinoma Preoperatively,” Cancer, Vol. 117, No. 4, 2009, pp. 254-263.

[34] K. Komatsu, Y. Nakanishi, T. Seki, A. Yoshino, F. Fuchinoue, S. Amano, A. Komatsu, M. Sugitani and N. Nemoto, "Application of Liquid-Based Preparation to Fine Needle Aspiration Cytology in Breast Cancer," Acta Cytologica, Vol. 52, No. 5, 2008, pp. 591-596. doi:10.1159/000325603
[35] H. Sartelet, E. Lagonotte, M. Lorenzato, I. Duval, C. Lechki, C. Rigaud, J. Cucherousset, A. Durlach, O. Graesslin, P. Abboud, M. Doco-Fenzy, C. Quereux, B. Costa, M. Polette, J. N. Munck and P. Birembaut, “Comparison of Liquid Based Cytology and Histology for the Evaluation of HER-2 Status Using Immunostaining and CISH in Breast Carcinoma," Journal of Clinical Pathology, Vol. 58, No. 8, 2005, pp. 864-871. doi:10.1136/jcp.2004.024224

[36] G. Fadda and E. D. Rossi, "Liquid-Based Cytology in Fine-Needle Aspiration Biopsies of the Thyroid Gland," Acta Cytologica, Vol. 55, No. 5, 2011, pp. 389-400. doi:10.1159/000329029

[37] K. Hashimoto, A. Morimoto, M. Kato, Y. Tominaga, N. Maeda, T. Tsuzuki, T. Yokoi and T. Nagasaka, "Immunocytochemical Analysis for Differential Diagnosis of Thyroid Lesions Using Liquid-Based Cytology,” Nagoya Journal of Medical Science, Vol. 73, No. 1-2, 2011, pp. 15-24.

[38] C. Gabriel, R. Achten and M. Drijkoningen, "Use of Liquid-Based Cytology in Serous Fluids: A Comparison with Conventional Cytopreparatory Techniques,” Acta Cytologica, Vol. 48, No. 6, 2004, pp. 825-835. doi:10.1159/000326453

[39] R. Laucirica, J. S. Bentz, R. J. Souers, P. G. Wasserman, B. A. Crothers, A. C. Clayton, M. R. Henry, B. A. Chmara, K. M. Clary, M. M. Fraig and A. T. Moriarty, "Do Liquid-Based Preparations of Urinary Cytology Perform Differently than Classically Prepared Cases? Observations from the College of American Pathologists Interlaboratory Comparison Program in Nongynecologic Cytology," Archives of Pathology \& Laboratory Medicine, Vol. 134, No. 1, 2010, pp. 19-22.

[40] Y. Norimatsu, N. Kawanishi, Y. Shigematsu, T. Kawabe, H. Ohsaki and T. K. Kobayashi, "Use of Liquid-Based Preparations in Urine Cytology: An Evaluation of LiquiPREP and BD SurePath,” Diagnostic Cytopathology, Vol. 38, No. 9, 2010, pp. 702-704. doi:10.1002/dc.21279

[41] E. Piaton, K. Hutin, J. Faynel, M. C. Ranchin and M. Cottier, "Cost Efficiency Analysis of Modern Cytocentrifugation Methods Versus Liquid Based (Cytyc Thinprep) Processing of Urinary Samples," Journal of Clinical Pathology, Vol. 57, No. 11, 2004, pp. 1208-1212. doi:10.1136/jcp.2004.018648

[42] V. Deshpande and G. T. McKee, "Analysis of Atypical Urine Cytology in a Tertiary Care Center," Cancer, Vol. 105, No. 6, 2005, pp. 468-475. doi:10.1002/cncr.21317

[43] E. C. Hwang, S. H. Park, S. I. Jung, D. D. Kwon, K. Park, S. B. Ryu and C. S. Park, "Usefulness of Liquid-Based Preparation in Urine Cytology," International Journal of Urology, Vol. 14, No. 7, 2007, pp. 626-629. doi:10.1111/j.1442-2042.2006.01731.x

[44] E. Piaton, J. Faynel, A. Ruffion, J. G. Lopez, P. Perrin and M. Devonec, "p53 Immunodetection of Liquid-Based Processed Urinary Samples Helps to Identify Bladder Tumours with a Higher Risk of Progression,” British Journal of Cancer, Vol. 93, No. 2, 2005, pp. 242-247. doi:10.1038/sj.bjc.6602684 
[45] J. S. Voss, B. R. Kipp, A. K. Krueger, A. C. Clayton, K. C. Halling, R. J. Karnes, M. R. Henry and T. J. Sebo, "Changes in Specimen Preparation Method May Impact Urine Cytologic Evaluation,” American Journal of Clinical Pathology, Vol. 130, No. 3, 2008, pp. 428-433. doi:10.1309/VP1XQ5GPQ687W1HU

[46] O. Raisi, C. Magnani, N. Bigiani, E. Cianciavicchia, R. D’Amico, U. Muscatello and C. Ghirardini, "The Diagnostic Reliability of Urinary Cytology: A Retrospective Study," Diagnostic Cytopathology, Vol. 40, 2012, in Press. doi:10.1002/dc.21716
[47] D. O. Sioutopoulou, L. I. Kampas, D. Gerasimidou, R. M. Valeri, I. Boukovinas, D. Tsavdaridis and C. T. Destouni, "Diagnosis of Metastatic Tumors in Cerebrospinal Fluid Samples Using Thin-Layer Cytology,” Acta Cytologica, Vol. 52, No. 3, 2008, pp. 304-308. doi:10.1159/000325511

[48] T. Tanaka, T. Kanda, S. Sakaguchi, S. Munakata and M. Ohmichi, "Vaginal Stump Metastasis from Sigmoid Colon Cancer,” Acta Cytologica, Vol. 56, No. 1, 2012, pp. 92-96. doi:10.1159/000330815 